\title{
Tumoral volume measured preoperatively by magnetic resonance imaging is related to survival in endometrial cancer
}

\author{
Pluvio J. Coronado1, Javier de Santiago-López¹, Javier de Santiago-García², \\ Ramiro Méndez ${ }^{3}$, Maria Fasero ${ }^{4}$, Miguel A. Herraiz ${ }^{1}$

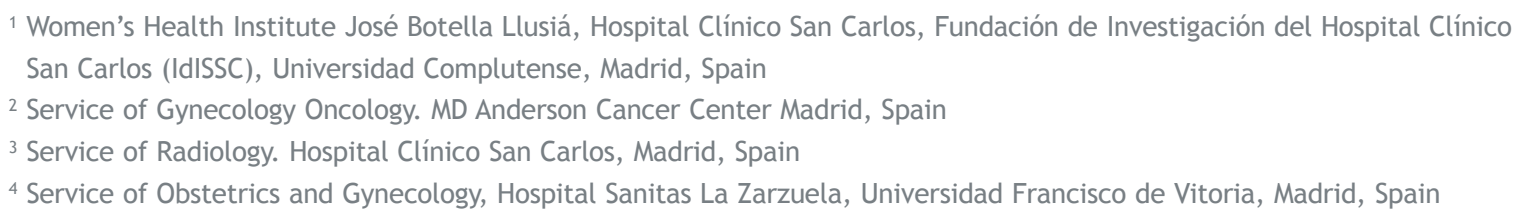

Radiol Oncol 2021; 55(1): 35-41.

Correspondence to: Pluvio J. Coronado, M.D., Ph.D., Instituto de Salud de la Mujer, Hospital Clinico San Carlos, C/Martín Lagos s/n, 28040, Madrid, Spain. E-mail: pcoronadom@sego.es

Disclosure: No potential conflicts of interest were disclosed.

\begin{abstract}
Background. The aim of the study was to determine if the endometrial tumor volume (TV) measured by magnetic resonance imaging (MRI-TV) is associated with survival in endometrial cancer and lymph nodes metastases (LN+). Patients and methods. We evaluated the MRI imaging and records of 341 women with endometrial cancer and preoperative MRI from 2008 to 2018. The MRI-TV was calculated using the ellipsoid formula measuring three perpendicular tumor diameters. Tumor myometrial invasion was also analyzed.

Results. Higher MRI-TV was associated with age $\geq 65 y$, non-endometrioid tumors, grade-3, deep-myometrial invasion, $\mathrm{LN}+$ and advanced FIGO stage. There were 37 patients with LN+ (8.8\%). Non-endometrioid tumors, deep-myometrial invasion, grade- 3 and MRI-TV $\geq 10 \mathrm{~cm}^{3}$ were the factors associated with $\mathrm{LN}+$. Using a receiver operating characteristic [ROC] curve, the MRI-TV cut-off for survival was $10 \mathrm{~cm}^{3}$ (area under curve [AUC] $=0.70 ; 95 \% \mathrm{Cl}: 0.61-0.73$ ). 5 years disease-free (DFS) and overall survival (OS) was significantly lower in MRI-TV $\geq 10 \mathrm{~cm}^{3}(69.3 \%$ vs. $84.5 \%$, and $75.4 \%$ vs. 96.1\%, respectively). MRI-TV was considered an independent factor of DFS (HR: 2.20,95\% Cl: 1.09-4.45, $p=0.029$ ) and OS (HR: $3.88,95 \% \mathrm{Cl}: 1.34-11.24, \mathrm{p}=0.012$ ) in multivariate analysis.

Conclusions. MRI-TV was associated with LN+, and MRI-TV $\geq 10 \mathrm{~cm}^{3}$ was an independent prognostic factor of lower DFS and OS. The MRI-TV can be auxiliary information to plan the surgery strategy and predict the adjuvant treatment in women with endometrial cancer.
\end{abstract}

Key words: tumoral volume; magnetic resonance image; endometrial cancer; recurrence; survival

\section{Introduction}

Endometrial cancer (EC) is the most common malignant tumor of the female reproductive tract in developed countries. Its prevalence has increased worldwide in the last years. ${ }^{1,2,3}$ In Spain, EC is the third most common cancer in women and the most common tumor of the female genital tract. ${ }^{4}$

Patient prognosis depends on different factors, including stage, depth of myometrial invasion
(DMI), lymphovascular space invasion, grade, and nodal status. Besides molecular alterations, DMI is one of the most important morphologic prognostic factors, correlating with tumor grade, presence of lymph node (LN) metastases and survival.5,6 Preoperatively, magnetic resonance imaging (MRI) can accurately assess the $\mathrm{DMI}^{4}$, whereas histologic type and grade only can be determined with endometrial tumor sampling. 
Standard surgical therapy for localized EC includes hysterectomy with bilateral salpingo-oophorectomy (HT \& BSO); however, the criteria for selecting patients for lymphadenectomy (LND) are still controversial. ${ }^{78}$ During the last two decades many authors have attempted to identify prognostic factors for stratifying women with EC into risk categories, in order to tailor the surgical and adjuvant treatment on the basis of estimated risk of tumor dissemination and recurrence. ${ }^{7}$ Different investigators have defined low-risk groups consistent with disease confined to the uterine corpus, histologic grade 1 or 2 , endometriod histologic subtype, less than 50\% DMI and tumor diameter of $2 \mathrm{~cm}$ or less to avoid LND.7,9,10 The LN evaluation is recommended in intermediate and high-risk EC. ${ }^{8}$ However, recent matched-pair studies have observed a lack of survival benefit of the systematic LND in those types of EC. ${ }^{11,12}$

Although tumor size is a factor that determines the stage of disease in many types of cancer (head and neck, breast, lung, renal, uterine cervix, vulva, uterine sarcoma, melanoma and soft tissue sarcoma), it is not involved in defining the stage of EC. ${ }^{13}$ Different authors have been trying to demonstrate the relationship between tumor diameter in resected uterine specimens and prognosis in EC. ${ }^{9,10}$ Naturally, postoperative assessment is not suitable for taking decisions of the better surgical approach and for selecting patients for neoadjuvant therapies. Therefore, preoperative assessment impacts the planning for surgery. ${ }^{14}$ Hence, some recent Japanese studies measured preoperatively tumor volumes by MRI, concluding that it is effective for predicting LN metastases and planning the LND. ${ }^{15,16}$ However, there is no good evidence about the role of tumor volume (TV) measured by MRI in the patient's prognosis.

The aim of this study was to determine if the tumor volume measured in the preoperative MRI study (MRI-TV) has a relationship with diseasefree survival (DFS) as a primary objective and with overall survival (OS) and LN involvement as secondary goals.

\section{Patients and methods}

A historical cohort of women diagnosed of EC between 2008 and 2018 was analyzed in Hospital Clinico San Carlos in Madrid, Spain. We included all women diagnosed of EC who underwent a presurgical MRI. All the patients had undergone HT \& BSO. Pelvic or pelvic and para-aortic LND were always performed by the same oncological team. Women diagnosed with uterine sarcomas or concomitant neoplasm, those who had been treated with primary chemo and/or radiotherapy or had been operated without presurgical MRI were excluded. The study was approved by the local Institutional Review Boards (No. 16/443-E). All patients were managed according to the guidelines approved by the Spanish Society of Gynecology and Obstetrics and all of them signed a specific consent form. ${ }^{17}$

All MRI studies were performed in 1.5T magnets (Signa Excite and Signa HDx, General Electric Medical Systems) using a standard protocol. Highresolution T2 weighted images were acquired in three perpendicular planes and then contrast enhanced T1 fat suppressed series were acquired in two or three different planes. Diffusion weighted sequences ( $b \geq 800 \mathrm{~s} / \mathrm{mm} 2)$ were acquired in most, but not in all the cases. All MR images were analyzed in the Radiology Service of the center by expert radiologists. The maximum tumor diameters were measured in three perpendicular axes, on the images that showed better the tumor-to-myometrium contrast (usually on the gadolinium enhanced series, having the T2 and diffusion images as references). The tumoral volume was calculated using the ellipsoid volume formula (length $\times$ height $\times$ width $\times[\pi / 6])$.

In addition, DMI was assessed following the standardized criteria using unenhanced T2 and gadolinium enhanced T1 series. DMI was defined as the distance between the myometrial interface and the deeper invasion point. Deep myometrial invasion was considered when the tumor affected $50 \%$ or more of the myometrial thickness.

In 237 cases in which it was the retrieved ultrasound reports, there was information about the DMI that was recorded and included. DMI was assessed during a real-time two-dimensional examination, and deep myometrial invasion was measured as the distance between endometriummyometrium junction and maximum tumor depth.

In our center, intraoperative frozen section evaluation (FSE) of DMI is routinely performed. This information was available and recorded in 189 cases. Two pathologists with wide experience in gynecological cancers where the ones that performed the intraoperative assessment of myometrial invasion and histological grade in all of the samples.

Continuous variables were described as median and interquartile range [p25-p75] and were compared using the T-test in normal distributions or the Mann-Whitney test in non-parametrical dis- 
tributions. Discrete variables were represented with absolute frequencies and percentages, and they were compared by the Chi-squared test or the Fisher's exact test in case of small cell comparisons. The McNemar test was used to assess the differences among the techniques evaluating the deep myometrial invasion. Receiver operating characteristic (ROC) curve was calculated to analyze the relation between the tumoral volume measured by MRI and the recurrence in order to identify the tumoral volume cut-off predicting the relapse. For survival analysis, Cox's method was used in order to assess which factors were directly associated with survival. Multivariate modeling using Cox's proportional hazard models, including the significant variables in univariate analysis, was performed to obtain a subset of independent predictors of DFS and OS. Hazard ratio (HR) with a 95\% confidence interval (CI) was calculated. The Kaplan-Meier method was used to estimate the survival distribution depending on the tumoral volume using the cut-off chosen. The Log-Rank (Mantel-Cox) test was used to calculate the statistical signification between the groups in relation to disease recurrence and death. All statistical tests were 2-sided and statistical significance was defined as a $p$-value lower than 0.05 . All computations were performed using IBM SPSS Statistic version 22.0 for Windows.

\section{Results}

The series baseline is shown in the Table 1 . The highest accuracy for detecting DMI was the intraoperative FSE (sensitivity 94\%, 95\% CI: 88-100\%) The MRI had sensitivity of $75 \%, 95 \%$ CI: $66-84 \%$ and transvaginal ultrasound 58\%, 95\% CI: 47-69\%, respectively. FSE was significantly more sensitive in detecting deep myometrial invasion than MRI $(p=0.049)$.

The median of MRI-TV was $8.2 \mathrm{~cm}^{3}$ (interquartile range [IQR]: 1.9-20.4). We found that higher MRITV was associated with advanced age, the highest histological grade 3, deep myometrial invasion, advanced International Federation of Gynecology and Obstetrics (FIGO) stage, LN involvement, disease recurrence and death (Table 2).

In order to identify a MRI-TV cut-off that could be considered a risk factor in EC, we performed a ROC curve. The more efficient cut-off in detection of tumor recurrence was a TV $=10 \mathrm{~cm}^{3}$, showing a $72.5 \%$ sensitivity and $59.8 \%$ specificity detecting the tumor recurrence (area under curve $[\mathrm{AUC}]=$ 0.70; 95\% CI: 0.61-0.73).
TABLE 1. Baseline patient's characteristics

\begin{tabular}{|c|c|}
\hline Variable & $N=341$ \\
\hline $\begin{array}{l}\text { Age (years) } \\
<65 y \\
\geq 65 y\end{array}$ & $\begin{array}{c}65.7[58.0-74.0] \\
186(54.5 \%) \\
155(45.5 \%)\end{array}$ \\
\hline $\begin{array}{l}\text { BMI }(\mathrm{kg} / \mathrm{m} 2) \\
\quad<30 \\
\geq 30\end{array}$ & $\begin{array}{c}29.3[24.8-33.0] \\
200(58.7 \%) \\
141(41.3 \%)\end{array}$ \\
\hline $\begin{array}{l}\text { Histologic subtype } \\
\text { Endometrioid } \\
\text { Mucinous } \\
\text { Squamous } \\
\text { Serous Papillary } \\
\text { Clear cells } \\
\text { Mixed mesodermal tumors } \\
\text { Undifferenced }\end{array}$ & $\begin{array}{c}278(81.5 \%) \\
5(1.5) \\
6(1.8 \%) \\
23(6.7 \%) \\
13(3.8 \%) \\
12(3.5 \%) \\
1(0.3 \%)\end{array}$ \\
\hline $\begin{array}{l}\text { Histological Grade } \\
\text { G1 } \\
\text { G2 } \\
\text { G3 }\end{array}$ & $\begin{array}{l}159(46.6 \%) \\
86(25.2 \%) \\
96(28.25 \%)\end{array}$ \\
\hline $\begin{array}{l}\text { Myometrial invasion } \\
\quad<50 \% \\
\geq 50 \%\end{array}$ & $\begin{array}{l}207(60.7 \%) \\
134(39.3 \%)\end{array}$ \\
\hline $\begin{array}{l}\text { FIGO stage } \\
\text { I } \\
\text { II } \\
\text { III } \\
\text { IV }\end{array}$ & $\begin{array}{l}270(79.2 \%) \\
15(4.4 \%) \\
45(13.2 \%) \\
11(3.2 \%)\end{array}$ \\
\hline $\begin{array}{l}\text { Surgical treatment } \\
\text { HT \& BSO alone } \\
\text { With pelvic lymphadenectomy } \\
\text { With pelvic \& paraaortic } \\
\text { lymphadenectomy }\end{array}$ & $\begin{array}{l}96(37.4 \%) \\
74(28.8 \%) \\
87(33.9 \%)\end{array}$ \\
\hline $\begin{array}{l}\text { Lymph nodes status ( } N=216 \text { ) } \\
\text { Negatives } \\
\text { Positives }\end{array}$ & $\begin{array}{l}179(82.9 \%) \\
37(17.1 \%)\end{array}$ \\
\hline $\begin{array}{l}\text { Adjuvant treatment } \\
\text { None } \\
\text { Irradiation } \\
\text { Chemotherapy } \\
\text { Irradiation and Chemotherapy }\end{array}$ & $\begin{array}{l}150(44.0 \%) \\
146(42.8 \%) \\
9(2.6 \%) \\
36(10.6 \%)\end{array}$ \\
\hline Follow-up (months) & 30.5 (18.5-46.2) \\
\hline Recurrence & $51(15.0 \%)$ \\
\hline Decrease & $29(8.5 \%)$ \\
\hline
\end{tabular}

Data are given as median and [interquartile range, p25-p75] or number (percentage).

$\mathrm{BMI}=$ body mass index; $\mathrm{FIGO}=$ International Federation of Gynecology and Obstetrics; HT \& BSO = hysterectomy with bilateral salpingooophorectomy

Analyzing only the 216 cases in which LND was performed, we found that the LN involvement was associated with the histological subtype, grade 3 and DMI. MRI-TV $\geq 10 \mathrm{~cm}^{3}$ was significantly associated with LN metastases (Table 3).

After a median follow-up of 30.5 months (IQR 18.5-46.2), 51 (15.0\%) women presented a relapse and $29(8.5 \%)$ deceased. Among the relapsed patients, 8 were alive and free of disease, 22 were alive with disease, and 21 died. Among the deceased patients, 21 women had disease-related death, and 8 died due to other causes. 

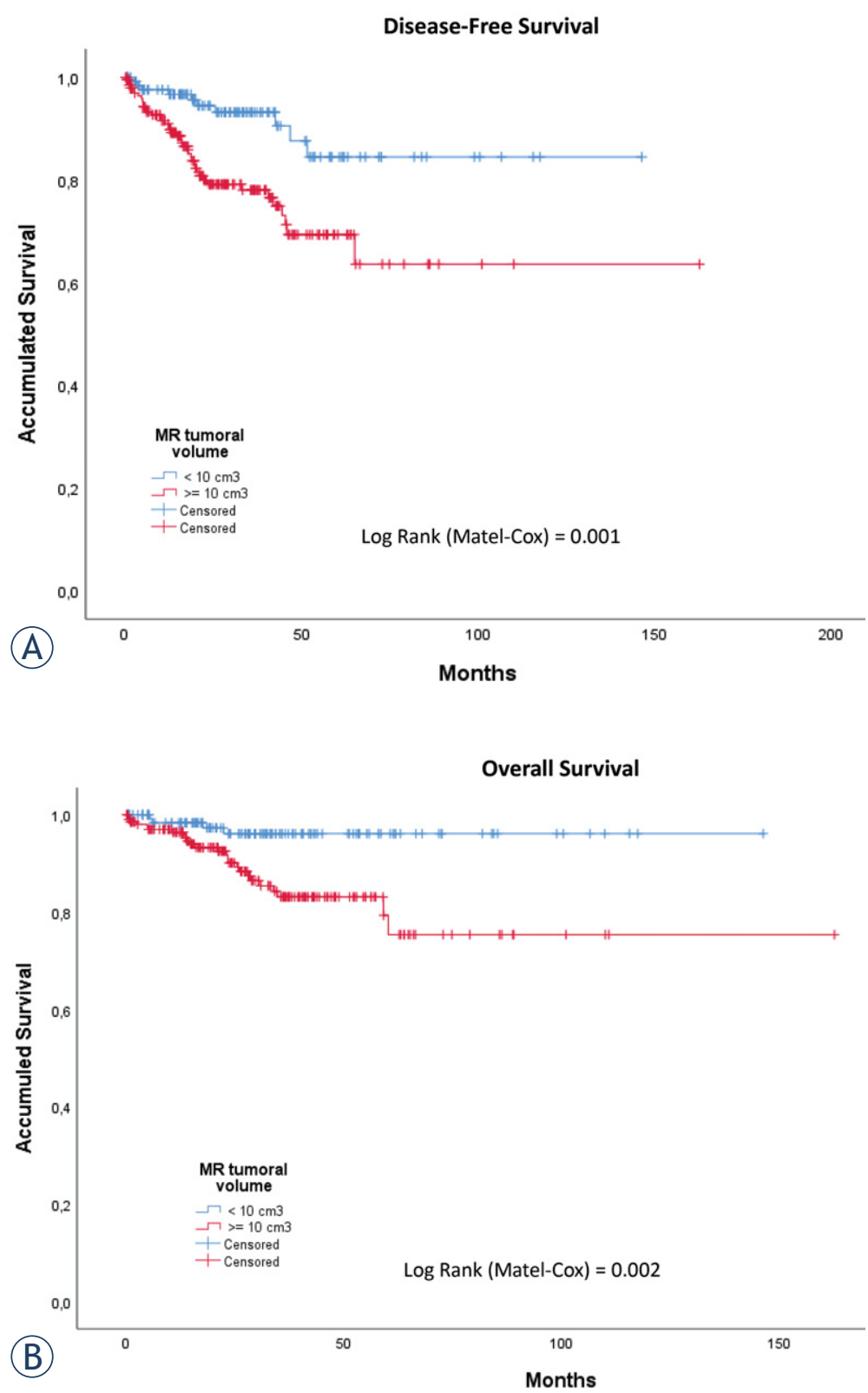

FIGURE 1: Kaplan Meier curves representing the survival in relation of tumoral volume measured by magnetic resonance. (A) Disease-free survival; (B) Overall Survival.

Survival analysis showed a 5-year DFS of $69.3 \%$ in tumors $\geq 10 \mathrm{~cm}^{3}$, which was significantly lower than in tumors of $<10 \mathrm{~cm}^{3}(84.5 \%$, Log Rank test: 0.001) (Figure 1A). In relation to OS, 5-year OS survival was lower in tumors $\geq 10 \mathrm{~cm}^{3}$ in comparison with tumors $<10 \mathrm{~cm}^{3}(75.4 \%$ vs. $96.1 \%$, Log Rank test: 0.002 ) (Figure $1 \mathrm{~B})$. Cox's univariate analysis identified the age $(p<0.001)$, MRI-TV $(p=0.001)$, non-endometrioid tumors $(\mathrm{p}=0.006)$, grade- 3 ( $\mathrm{p}$ $<0.001)$, myometrial invasion $(\mathrm{p}=0.009)$ and advanced stage $(\mathrm{p}<0.001)$ as predicting factors of
TABLE 2. Relation between tumor volume measured by magnetic resonance and pathological factors in 341 endometrial cancer

\begin{tabular}{|c|c|c|}
\hline Variables & $\begin{array}{c}\text { MR tumor volume } \\
\mathrm{cm} 3\end{array}$ & $p$ value* \\
\hline Tumoral volume & $8.2(1.9-20.4)$ & - \\
\hline $\begin{array}{l}\text { Age (years) } \\
\quad<65 \\
\geq 65\end{array}$ & $\begin{array}{c}5.4(1.5-15.4) \\
11.0(2.8-30.0)\end{array}$ & 0.001 \\
\hline $\begin{array}{l}\text { BMI }(\mathrm{kg} / \mathrm{m} 2) \\
\quad<30 \\
\quad \geq 30\end{array}$ & $\begin{array}{l}9.1(2.3-22.3) \\
7.5(1.6-23.6)\end{array}$ & 0.525 \\
\hline $\begin{array}{l}\text { Histologic subtype } \\
\text { Endometrioid } \\
\text { Non endometrioid }\end{array}$ & $\begin{array}{c}7.9(1.8-20.4) \\
12.4(3.3-40.1)\end{array}$ & 0.859 \\
\hline $\begin{array}{l}\text { Histological Grade } \\
\text { G1-G2 } \\
\text { G3 }\end{array}$ & $\begin{array}{c}6.7(1.3-17.2) \\
13.8(4.6-41.0)\end{array}$ & $<0.001$ \\
\hline $\begin{array}{l}\text { Myometrial invasion } \\
\quad<50 \% \\
\geq 50 \%\end{array}$ & $\begin{array}{c}4.6(1.2-15.4) \\
14.1(5.7-35.1)\end{array}$ & $<0.001$ \\
\hline $\begin{array}{l}\text { FIGO stage } \\
\text { I-II } \\
\text { III-IV }\end{array}$ & $\begin{array}{c}7.6(1.5-19.6) \\
15.6(6.5-44.7)\end{array}$ & $<0.001$ \\
\hline $\begin{array}{l}\text { Lymph node status } \\
(\mathrm{N}=216) \\
\text { Negatives } \\
\text { Positives }\end{array}$ & $\begin{array}{c}9.3(3.3-20.9) \\
15.6(6.3-40.7)\end{array}$ & 0.008 \\
\hline $\begin{array}{l}\text { Recurrence } \\
\text { No } \\
\text { Yes }\end{array}$ & $\begin{array}{c}7.6(1.7-17.4) \\
22.4(5.6-49.2)\end{array}$ & $<0.001$ \\
\hline $\begin{array}{l}\text { Overall Survival } \\
\text { Alive } \\
\text { Death }\end{array}$ & $\begin{array}{c}8.0(1.8-18.6) \\
30.5(9.6-56.4)\end{array}$ & $<0.001$ \\
\hline
\end{tabular}

Data are gives as median (p25-p75).

* = Mann-Whitney $\mathrm{U}$ independent sample test; $\mathrm{BMI}=$ body mass index $\mathrm{FIGO}=$ International Federation of Gynecology and Obstetrics

recurrence (Table 4). MRI-TV $(p=0.029)$, grade 3 $(\mathrm{p}<0.001)$ and advanced stage (III-IV) $(\mathrm{p}=0.047)$ were the independent factors of recurrence in the multivariate analysis (Table 5). In relation with OS, the age $(p<0.001)$, MRI-TV $(p=0.005)$, grade- $3(p=$ $0.001)$ and advanced stage $(p=0.001)$ were the predictor factors of mortality (Table 4$)$. In multivariant analysis, MRI-TV $(p=0.012)$ and grade- $3(p=0.011)$ were the independent factors of OS.

\section{Discussion}

In woman with EC, the preoperative MRI-TV correlates with the LN involvement and is an independent prognostic factor for DFS and OS in this series. A cut-off of $10 \mathrm{~cm}^{3}$ determines properly the cases that might present with positive LN and should undergo LND. It also adds information about poor prognosis and the need for adjuvant treatment. The relation between relapse and MRI- 
TV in EC has been described by other studies. A Japanese study in 667 women with EC and using a volume index defined as the product of the maximum diameter in the 3 planes (longitudinal, anteroposterior and horizontal), found a MRI-TV $\geq 36 \mathrm{~cm}^{3}$ as an independent prognostic factor of OS (HR 2.0; 95\% CI:1.3-3.1). ${ }^{18}$ This study used as cutoff a fixed value of MRI-TV based on other study from the same group ${ }^{16}$, and considered the volume of the endometrial cavity as a single measure of three measures. In our study, the endometrial cavity was considered as ellipsoid, more like the real shape of the endometrial tumor. However, both studies have similar outcomes, suggesting the MRI-TV is an independent prognostic factor to take in consideration in the preoperative assessment of women diagnosed of EC. In addition, the MRI-TV in the Japanese study was significantly associated with LN involvement, especially when TV was $\geq 125 \mathrm{~cm}^{3}$. Similar finding was also found in our study when we analyzed the MRI-TV both as continuous variable and as qualitative using 10 $\mathrm{cm}^{3}$ as cut-off value. The differences in the cut-off may be because of the different method to measure the endometrial cavity. A Japan-Korea cooperative study with the same methodology, found similar results in 327 cases, showing a MRI-TV $>36 \mathrm{~cm}^{3}$ as an independent prognostic factor of LN metastases. ${ }^{19}$ Other studies analyzing the preoperative metabolic volume by PET/CT and MRI found the tumor volume as an independent prognostic factor for DFS and it was significantly associated with recurrence in patients with endometrioid EC. ${ }^{20}$

MRI has been considered as the best technique to diagnose deep myometrial invasion. However, in our series, the best option was FSE. A recent study found a higher performance using fusion of T2-weighted magnetic with diffusion-weighted MR images, with a sensitivity of $92.3 \%$ and specificity of $95.5 \%$ for deep myometrial invasion detection. ${ }^{21}$ In relation to ultrasound, we obtained a poor result in order to detect the deep myometrial invasion. A recent study analyzing 210 women with proven EC found that both subjective assessment and objective ratios were significant predictors of the myometrial invasion, but subjective assessment was confirmed as the most reliable method to assess myometrial invasion (sensitivity $79 \%$ and specificity $73 \%$ ). ${ }^{22}$ A meta-analysis of 35 studies with 6387 women diagnosed of EC found that FSE had a significantly better diagnostic performance than intraoperative gross evaluation (sensitivity $84 \%$ vs. $71 \%$ ) for the intraoperative diagnosis of deep myometrial invasion.
TABLE 3. Predictor factors of lymph node metastases in 216 cases of endometrial cancer with known lymph node status

\begin{tabular}{lccc}
\hline Variables & $\begin{array}{c}\text { No lymph node } \\
\text { metastases } \\
\mathbf{N}=179\end{array}$ & $\begin{array}{c}\text { Lymph node } \\
\text { metastases } \\
\mathbf{N}=37\end{array}$ & p value \\
\hline $\begin{array}{c}\text { Age (years) } \\
<65\end{array}$ & $78(43.6 \%)$ & $12(32.4 \%)$ & 0.211 \\
$\geq 65$ & $101(56.4 \%)$ & $25(67.6 \%)$ & \\
Histologic subtype & $147(82.1 \%)$ & $23(62.2 \%)$ & 0.007 \\
$\quad$ Endometrioid & $32(17.9 \%)$ & $14(37.8 \%)$ & \\
$\quad$ Non endometrioid & $118(56.9 \%)$ & $13(35.1 \%)$ & $<0.001$ \\
Histological Grade & $61(43.1 \%)$ & $24(64.9 \%)$ & \\
$\quad$ G1-G2 & & & \\
G3 & $90(50.3 \%)$ & $8(21.6 \%)$ & 0.001 \\
Myometrial invasion & $89(49.7 \%)$ & $29(78.4 \%)$ & \\
$<50 \%$ & & & \\
$\geq 50 \%$ & $43(24.0 \%)$ & $6(16.2 \%)$ & \\
Maximum tumor size & $136(76.0 \%)$ & $31(83.8 \%)$ & \\
$<2 \mathrm{~cm}$ & & $5(13.5 \%)$ & 0.013 \\
$\geq 2 \mathrm{~cm}$ & $61(34.1 \%)$ & $32(86.5 \%)$ & \\
\hline MR tumor volume & $118(65.9 \%)$ & & \\
$<10 \mathrm{~cm}^{3}$ & & & \\
$\geq 10 \mathrm{~cm}^{3}$ & & & \\
\hline
\end{tabular}

TABLE 4. Analysis of disease-free and overall survival using Cox regression model

\begin{tabular}{|c|c|c|c|c|}
\hline Variables & Disease-free & $p$ value & overall & $p$ value \\
\hline Age (continue, years) & 1.06 (1.03-1.09) & $<0.001$ & $1.09(1.05-1.13)$ & $<0.001$ \\
\hline $\begin{array}{l}\text { MRI tumor volume } \\
\quad<10 \mathrm{~cm}^{3} \\
\quad \geq 10 \mathrm{~cm}^{3}\end{array}$ & $2.99(1.50-5.99)$ & 0.001 & $\frac{1}{4.50(1.56-12.93)}$ & 0.005 \\
\hline $\begin{array}{l}\text { Histologic subtype } \\
\text { Endometrioid } \\
\text { Non endometrioid }\end{array}$ & $2.55(1.30-5.01)$ & 0.006 & $\begin{array}{c}1 \\
2.40(0.97-5.95)\end{array}$ & 0.052 \\
\hline $\begin{array}{l}\text { Histological Grade } \\
\text { G1-G2 } \\
\text { G3 }\end{array}$ & $4.02(2.31-6.98)$ & $<0.001$ & $3.55(1.71-7.37)$ & 0.001 \\
\hline $\begin{array}{l}\text { Myometrial invasion } \\
\quad<50 \% \\
\quad \geq 50 \%\end{array}$ & $2.10(1.20-3.64)$ & 0.009 & $1.89(0.91-3.93)$ & 0.088 \\
\hline $\begin{array}{l}\text { FIGO stage } \\
\text { |-II } \\
|||-| V\end{array}$ & $\frac{1}{6.70(3.83-11.72)}$ & $<0.001$ & $\begin{array}{c}1 \\
3.94(1.79-8.68)\end{array}$ & 0.001 \\
\hline
\end{tabular}

Data are given in Hazard Ratio (95\% confidence interval).

$\mathrm{FIGO}=$ International Federation of Gynecology and Obstetrics; MRI = magnetic resonance image

The tumoral size has been associated with several classic prognostic factors and it has been considered as a prognostic factor in many human tumors, including gynecological tumors such as cervix, vulva and breast, but not in ovarian and EC. ${ }^{13}$ The Mayo clinic criteria in $\mathrm{EC}^{9}$, suggested the tumoral size $>2 \mathrm{~cm}$ as high risk of LN metastases. In our series, the MRI-TV was associated with the classical prognostic factors in the EC. This finding was also found by other authors. ${ }^{18,19}$ High-risk clinico- 
TABLE 5. Multivariant analysis of disease-free and overall survival using Cox regression model with the classic histological prognostic factors

\begin{tabular}{lcccc}
\hline Variables & $\begin{array}{c}\text { Disease-free } \\
\text { survival }\end{array}$ & p value & $\begin{array}{c}\text { Overall } \\
\text { survival }\end{array}$ & p value \\
$\begin{array}{l}\text { MRI tumor volume } \\
<10 \mathrm{~cm}^{3}\end{array}$ & 1 & & 1 & \\
$\quad \geq 10 \mathrm{~cm}^{3}$ & $2.20(1.09-4.45)$ & 0.029 & $3.88(1.34-11.24)$ & 0.012 \\
$\begin{array}{c}\text { Histologic subtype } \\
\text { Endometrioid }\end{array}$ & 1 & & 1 & \\
$\quad$ Non endometrioid & $1.06(0.50-2.24)$ & 0.873 & $1.16(0.43-3.16)$ & 0.766 \\
$\begin{array}{l}\text { Histological Grade } \\
\quad \text { G1-G2 }\end{array}$ & 1 & & 1 & \\
$\quad$ G3 & $3.60(1.95-6.66)$ & $<0.001$ & $3.07(1.47-6.41)$ & 0.003 \\
$\begin{array}{l}\text { Myometrial invasion } \\
\quad<50 \%\end{array}$ & 1 & & & \\
$\quad \geq 50 \%$ & $1.77(1.01-4.46)$ & 0.047 & $1.51(0.72-3.17)$ & 0.279 \\
\hline
\end{tabular}

Data are given in Hazard Ratio ( $95 \%$ confidence interval).

MRI = magnetic resonance image

pathological features (such as deep myometrial invasion, histological grade and non-endometrioid subtypes), LN involvement and advanced FIGO stages were increased with higher MRI-TV, suggesting a positive correlation between it and the adverse outcomes.

Sentinel node biopsy is a good way to have LN status information and to avoid the complete LND. ${ }^{23}$ However, this procedure is not free of complications and a preoperative information predicting the LN involvement could help in the process of making the decision of whether or not to perform the LN assessment. Based on our results, we suggest performing a LN assessment in EC with large TV. Nevertheless, we cannot set the best TV cut-off from which assess the LN status.

In our study, the TV was measured by different radiologist, and even though we used the same criteria, it could be a limitation because of the interobserver variability that can alter the endometrial measures. On the other hand, the type of adjuvant treatment and the type of surgery could differ between the cases and this could have influenced the patients' survival. The main strength of this study, with respect to others that also analyzed the TV, is the use of an ellipsoid to measure the TV, because is the shape more similar to endometrial cavity, and the result of the product of three single measures results on a cubic shape.

\section{Conclusions}

In conclusion, the TV measured by MRI is a predictor of high-risk pathological factors, and it is positively associated with LN involvement. The
TV higher than $10 \mathrm{~cm}^{3}$ is related with poor prognosis in univariate and multivariate analysis. The preoperative measure of TV by MRI can therefore be a good tool to determine the best surgery strategy in EC.

\section{References}

1. Morice P, Leary A, Creutzberg C, Abu-Rustum N, Darai E. Endometrial cancer. Lancet 2016; 387: 1094-108. doi: 10.1016/S0140-6736(15)00130-0

2. Bray F, Dos Santos Silva I, Moller H, Weiderpass E. Endometrial cancer incidence trends in Europe: underlying determinants and prospects for prevention. Cancer Epidemiol Biomarkers Prev 2005; 14: 1132-42. doi: 10.1158/1055-9965.EPI-04-0871

3. Siegel R, Miller KD, Jemal A. Cancer statistics 2015. CA Cander J Clin 2015; 65: 5-29. doi: 10.3322/caac.21254

4. Galceran J, Ameijide A, Carulla M, Mateos A, Quirós JR, Rojas D, et al. REDECAN Working Group. Cancer incidence in Spain, 2015. Clin Trans/ Oncol 2017; 19: 799-825. doi: 10.1007/s12094-016-1607-9

5. Creasman W. Revised FIGO staging for carcinoma of the endometrium. Int Gynaecol Obstet 2009; 105: 109. doi: 10.1016/j.ijgo.2009.02.010

6. Beddy P, O'Neill AC, Yamamoto AK, Addley HC, Reinhold C, Sala E. FIGO staging system for endometrial cancer: added benefits of MR imaging. Radiographics 2012; 32: 241-54. doi: 10.1148/rg.321115045

7. Mariani A, Dowdy SC, Cliby WA, Gostout BS, Jones MB, Wilson TO, et al. Prospective assessment of lymphatic dissemination in endometrial cancer: a paradigm shift in surgical staging. Gynecol Oncol 2008; 109: 11-8. doi: 10.1016/j.ygyno.2008.01.023

8. Colombo N, Creutzberg C, Amant F, Bosse T, González-Martín A, Ledermann $\mathrm{J}$, et al. ESMO-ESGO-ESTRO Endometrial Consensus Conference Working Group. ESMO-ESGO-ESTRO Consensus conference on endometrial cancer: diagnosis, treatment and follow-up. Int J Gynecol Cancer 2016; 26: 2-30. doi: 10.1097/IGC.0000000000000609.

9. Mariani A, Webb MJ, Keeney GL, Haddock MG, Calori G, Podratz KC. Lowrisk corpus cancer: is lymphadenectomy or radiotherapy necessary? Am J Obstet Gynecol 2000; 182: 1506-19. doi: 10.1067/mob.2000.107335

10. Alhilli, MM, Podratz KC, Dowdy SC, Bakkum-Gamez JN, Weaver AL, McGree ME et al. Preoperative biopsy and intraoperative tumor diameter predict lymph node dissemination in endometrial cancer. Gynecol Oncol 2013; 128 294-9. doi: 10.1016/j.ygyno.2012.10.009

11. Coronado PJ, Rychlik A, Martínez-Maestre MA, Baquedano L, Fasero M, García-Arreza A, et al. Role of lymphadenectomy in intermediate-risk endometrial cancer: a matched-pair study. J Gynecol Oncol 2018; 29: e1. doi: 10.3802/jgo.2018.29e1

12. Coronado PJ, Fasero M, Baquedano L, Martinez-Maestre MA, Casado A Vidart JA, et al. Impact of the lymphadenectomy in high-risk histologic types of endometrial cancer: a matched-pair study. Int J Gynecol Cancer 2014; 24: 703-12. doi: 10.1097/IGC.0000000000000120

13. TNM atlas. Illustrated guide to the TNM/PTNM classification of malignant tumours. In: Writtekind Ch, Greene FL, Hutter RVP, Klimpfinger M, Sobin LH, editors. 5th edition. Berlin, Heidelberg: Springer-Verlag; 2004.

14. Milam MR, Java J, Walker JL, Metzinger DS, Parker LP, Coleman RL Gynecologic Oncology Group. Nodal metastasis risk in endometrioid endometrial cancer. Obstet Gynecol 2012; 119: 286-92. doi: 10.1097/ AOG.0b013e318240de51

15. Todo Y, Sakuragi N, Nishida R, Yamada T, Ebina Y, Yamamoto R, Fujimoto $\mathrm{S}$. Combined use of magnetic resonance imaging, CA 125 assay, histologic type, and histologic grade in the prediction of lymph node metastasis in endometrial carcinoma. Am J Obstet Gynecol 2003; 188: 1265-72. doi: $10.1067 / \mathrm{mob} .2003 .318$

16. Todo $Y$, Okamoto $K$, Hayashi M, Minobe S, Nomura E, Hareyama $H$, et al. A validation study of a scoring system to estimate the risk of lymph node metastasis for patients with endometrial carcinoma for tailoring the indication of lymphadenectomy. Gynecol Oncol 2007; 104: 623-8. doi: 10.1016/j. ygyno.2006.10.002 
17. Oncoguía SEGO (ES). [Guide of practice clinic in cancer gynaecology and senology]. [Spanish]. Madrid: Publicaciones SEGO; 2010.

18. Todo $\mathrm{Y}$, Watari H, Okamoto $\mathrm{K}$, Hareyama H, Minobe S, Kato H, et al. Tumor volume successively reflects the state of disease progression in endometrial cancer. Gynecol Oncol 2013; 129: 472-7. doi: 10.1016/j.ygyno.2013.02.034

19. Todo Y, Choi HJ, Kang S, Kim JW,Nam JH, Watari H, et al. Clinical significance of tumor volume in endometrial cancer: a Japan-Korea cooperate study. Gynecol Oncol 2013; 131: 294-8. doi: 10.1016/j.ygyno.2013.08.008

20. Chung HH, Lee I, Kim HS, Kim JW, Park NH, Song YS, et al. Prognostic value of preoperative metabolic tumor volume measured by ${ }^{18} \mathrm{~F}-\mathrm{FDG}$ PET/CT and MRI in patients with endometrial cancer. Gynecol Oncol 2013; 130: 446-51. doi: 10.1016/j.ygyno.2013.06.021

21. Guo Y, Wang P, Wang P, Gao W, Li F, Yang X, et al. Myometrial invasion and overall staging of endometrial carcinoma: assessment using fusion of $\mathrm{T} 2$ weighted magnetic resonance imaging and diffusion-weighted magnetic resonance imaging. Onco Targets Ther 2017; 10: 5937-43. doi: 10.2147/OTT. S145763

22. Frühauf F, Zikan M, Semeradova I, Dundr P, Nemejcova K, Dusek L, et al. The diagnostic accuracy of ultrasound in assessment of myometrial invasion in endometrial cancer: subjective assessment versus objective techniques. Biomed Res Int 2017; 2017: 1318203. doi: 10.1155/2017/1318203

23. Ruiz R, Gorostidi M, Jaunarena I, Goiri C, Aguerre J, Lekuona A. Sentinel node biopsy in endometrial cancer with dual cervical and fundal indocyanine green injection. Int J Gynecol Cancer 2018; 28: 139-44. doi: 10.1097/ IGC.0000000000001151 